\title{
A patrimonialização da memória da cultura popular brasileira no Museu de Folclore Edison Carneiro ${ }^{1}$
}

\author{
Vânia Dolores Estevam de Oliveira2 \\ Universidade Federal de Goiás
}

\begin{abstract}
RESUMO: Texto focalizando as ações do Museu de Folclore Edison Carneiro de 1968 a 1984, à luz dos conceitos de memória social (HALLBWACHS), de patrimônio e de vontade de memória (NAMER). 0 período em pauta compreende duas fases da atuação institucional, aqui denominadas de 'folclorista' e 'antropológica', que refletem as mudanças nos rumos da política cultural praticada durante o período militar.
\end{abstract}

PALAVRAS-CHAVE: Museu de Folclore Edison Carneiro; Memória Social; Patrimônio; Museologia; Museus de folclore

ABSTRACT: Text focusing on the actions of Edison Carneiro Folklore Museum from 1968 to 1984, under the concepts of social memory (HALLBWACHS), cultural heritage and 'will of memory' (Namer). The period in question consists of two phases of institutional practice, which reflect changes in the direction of cultural policy practiced during the military period in Brazil.

KEYWORDS: Edison Carneiro Folklore Museum, Social memory, cultural heritage; Museology; folklore museums

Este texto visa discutir as interfaces entre memória social, patrimônio constituído, e museus ou "casas do patrimônio" como resultantes da vontade de memória das pessoas e instituições, tendo como foco o Museu de Folclore Edison Carneiro, de 1968 a 1984. Na primeira fase, o Museu refletia o pensamento museal dos folcloristas e funcionava como 'laboratório' para estudantes de Museologia. A segunda fase, denominada 'antropológica', acontece em tempos de abertura democrática, em que a cultura popular é entendida como marca da diversidade e produto cultural.

A perspectiva será sobre a ação museológica ao longo da trajetória do Museu. Como suporte teórico, os conceitos de memória social (Halbwachs, 1952 e 1990),

\footnotetext{
${ }^{1}$ Este texto é inspirado no capítulo 3 da tese de doutoramento em Memória Social, sob o título Museu de Folclore Edison Carneiro: poder, resistência e tensões na construção da memória da cultura popular brasileira, defendida em junho de 2011 pela UNIRIO, sob orientação da Profa Vera Dodebei. 2 Museóloga, doutora em Memória Social, docente do bacharelado em Museologia da Faculdade de Ciências Sociais da Universidade Federal de Goiás.
} 
de lugar de memória (Nora, 1993) e de vontade de memória (Namer, 1987). As ideias de Chauí (1989) e Ortiz (1994) vão iluminar a compreensão sobre a política cultural voltada para a cultura popular no Brasil.

Memória social, ou memória coletiva é a memória da sociedade, ou "da totalidade significativa em que se inscrevem e transcorrem as micro memórias pessoais, elos de uma cadeia maior" (Duarte, 2003: 306). O patrimônio é uma "categoria de pensamento extremamente importante para a vida social e mental de qualquer coletividade humana", que pode ser observada em todas as sociedades através da história, não só as modernas e ocidentais (Gonçalves, 2003: 22), mas ao contrário do que pensamos, não faz parte do mundo natural, sendo uma construção histórica. E por ser assim, tanto a memória coletiva quanto a individual, é preexistente ao patrimônio, que é o mediador entre as representações da memória preservadas nos museus. 0 patrimônio, como "mediador entre a memória social e os museus [...] e demais instituições de memória, constrói, forma as pessoas" (Gonçalves, 2003: 27), conformando também as sociedades, em todas as suas formas.

No Brasil a institucionalização do patrimônio e a proliferação dos museus ocorreram trilhando caminhos paralelos, embora por trajetórias distintas. Ao lado das primeiras incursões voltadas para a preservação, ao longo dos séculos XVIII e XIX, e início do XX, surgem também os primeiros museus. A Inspetoria Nacional de Monumentos, reconhecidamente um dos principais antecedentes da criação do Serviço do Patrimônio Histórico e Artístico Nacional (Magalhães, 2004 e Chagas, 2003), é criada no Museu Histórico Nacional em 1934. Com o Estado Novo instituise o tombamento, com a edição do Decreto Lei 25, de 1937, e é também quando o fenômeno museu toma grande impulso. 0 projeto político de identificação nacional pelo conhecimento e exaltação dos feitos heróicos do passado, já via nos museus um importante instrumento. Chagas (2003: 50) afirma que a "cidadela do patrimônio" contém o museu "e suas especificidades, como uma espécie de 
bastião", e tem "frequentemente contribuído, de dentro para fora e de fora para dentro, para forçar as portas e dilatar o domínio patrimonial”. A partir do Estado Novo os museus passam a servir de bastiões aos propósitos patrimoniais e, desde então, esta parceria vem se aprofundando, até que nos anos 1980, o patrimônio passou a integrar o discurso museal com mais ênfase.

O desejo preservacionista é comungado pelas duas instituições, e vem servindo como anel de compromisso nessa união. Contudo, se patrimônio e museu vivem um longo casamento, com os conflitos inerentes ao matrimônio, folclore e patrimônio não se falaram durante um bom tempo, salvo nas exceções que sempre ocupam as brechas propiciadoras das mudanças de paradigmas. As expressões da cultura ligadas às massas populares rurais ou urbanas não fizeram parte das preocupações preservacionistas dos ideólogos do patrimônio no Brasil, à exceção de Mário de Andrade, de uma minoria no interior do próprio IPHAN, e claro, dos folcloristas. A razão parece residir nas motivações que conduzem à preservação de determinados bens em detrimento de outros. Para que a ação preservacionista seja iniciada, não é suficiente a ameaça de perda ou dano; "é preciso, e esse não é um ponto sem importância, que o sujeito da ação identifique no objeto a ser preservado algum valor [...] Perigo e valor. Perigo e valor imaginados são as palavras-chave para a ação preservacionista" (Chagas, 2003: 33). Decorre daí a popularidade do conceito e expressão "lugar de memória" entre os técnicos que atuam em instituições de memória. A instituição de "lugares de memória" é ocasionada pela ameaça, ou pela perda efetiva dos elementos que conformam a memória social, "verdadeira, intocada [...], integrada, ditatorial e inconsciente de si mesma, organizadora e todo-poderosa, espontaneamente atualizadora..." (Nora, 1993: 8). 
No Brasil - sob inspiração do Romantismo, a princípio, e depois das ações da UNESCO - coube ao Movimento Folclórico Brasileiro ${ }^{3}$ essa primazia do olhar preservacionista sobre o folclore e a cultura popular, em que se vislumbravam também valores e perigos. As ideias de fragilidade, ameaças de desfiguração e perda definitiva permeiam os escritos e anotações de campo dos estudiosos do folclore. Os estudiosos do folclore que formavam aquele Movimento criaram sua representante institucional, a Campanha de Defesa do Folclore Brasileiro em 1958, que investiu nos museus como fortes aliados, estimulando e apoiando a criação de museus em todo o país.

Após os rumos tomados pelo golpe militar de 1964, e com a ameaça de desmantelamento da Instituição, em 1968 é firmado um convênio entre a Campanha e o Museu Histórico Nacional (MHN), para instalação do Museu de Folclore, graças ao empenho de Renato Almeida (1895-1981), líder do Movimento Folclórico e terceiro diretor executivo da Instituição. A "vontade de memória" (Namer, 1987) da Instituição se concretiza na criação do Museu, reunindo e organizando um minucioso arquivo com os documentos relativos à sua história, divulgando e publicando o conhecimento produzido até então.

0 medo da perda iminente e do apagamento levou à criação de um lugar para guarda e preservação das manifestações da cultura popular, na forma de objetos, indumentárias de folguedos, quadrinhas, cantos e depoimentos gravados. Com a criação do Museu de Folclore, a "memória se enraíza no concreto, no espaço, no gesto, na imagem, no objeto" como reação à iminência da destruição. Neste caso, um "lugar de memória", segundo conceituado por Nora (1993: 9), com a configuração de museu.

\footnotetext{
${ }^{3}$ Sobre o Movimento Folclórico Brasileiro, a obra mais completa até o momento é a de Luís Rodolfo Vilhena (1997).
} 
A instalação do primeiro núcleo do Museu de Folclore aconteceu em "pavilhão" no Parque do Museu da República, que nessa época constituía uma seção do MHN. Concretizava-se também desse modo a expressão museológica do pensamento de Gustavo Barroso sobre o nacional: a elite e o povo estavam finalmente lado a lado, representando e reconstruindo a memória brasileira (Abreu, 1990: 69). Em relatório escrito três anos após a criação, o espaço é assim descrito: "prédio de 5 cômodos, assim distribuídos": 3 salas para exposições, 1 copa, "atualmente, servindo de escritório", 1banheiro "em estado precário" e 2 áreas externas descobertas (Carvalho, 1971: 1).

A notícia da inauguração do Museu de Folclore traz um resumo do que foi apresentado nos "vários mostruários do Museu" em sua primeira exposição, "com as suas coleções dispostas, conforme o gênero: instrumentos musicais, cerâmica figurativa e utilitária, objetos de pano e madeira, cestaria, esculturas etc., dentro do critério regional" (Noticiário, 1968: 176).

0 acervo reunido para a inauguração do Museu de Folclore contava pelo menos, com dois mil e setecentos objetos (Noticiário, 1968: 105 e Nascimento, 1988: 6), compreendendo "extrema variedade de peças, oriundas de diferentes pontos do território nacional, havendo predominância da ergologia folclórica nordestina". Reunia "peças de Vitalino [...], Ezequiel, Marluce etc.", além de utensílios utilitários em madeira, "peças típicas do gaúcho (coleções de punhais de prata?), bombachas, peças de couro etc., de cultos afro-brasileiros, trançados, cestaria etc." (Salles, 1968: 1).

O Museu de Folclore da Campanha de Defesa do Folclore Brasileiro estava criado. Agora se tratava do mais difícil: dar continuidade à sua existência e ampliar suas instalações e área de atuação. O segundo diretor do Museu de Folclore foi o pernambucano, Aécio de Oliveira, que em 1969, ainda estudante do Curso de Museus, foi "nomeado diretor" do Museu de Folclore pelo Comandante Léo 
Fonseca e Silva 4 . Segundo Aécio de Oliveira, os alunos utilizavam o nascente Museu como uma espécie de "laboratório, um centro de estudos experimentais da Faculdade de Museologia". Elaboravam e montavam exposições temporárias e davam início à documentação do acervo repassado pela Campanha de Defesa do Folclore Brasileiro (Especialista, 1969). O primeiro livro de registro data de 1969 (Carvalho, 1971: 2-5).

A visitação do pequeno museu, "apesar de pouco conhecido e sem nenhuma divulgação" ultrapassava os 11 mil visitantes. Tinha então apenas três funcionários: uma museóloga, uma recepcionista e um guarda de sala (Carvalho, 1971). Em 1972 o Museu deixaria o "pequeno pavilhão", sendo deslocado para o térreo do prédio anexo do Museu da República, ocupando "três salas de exposições, um gabinete e uma pequena sala para as pesquisas feitas por estudantes" (Mseu, 1972: 2).

O Museu de Folclore prossegue divulgando e promovendo o folclore, apesar das limitações físicas e financeiras. Os relatórios, mesmo frisando o espaço exíguo, trazem as notícias de cursos, conferências, palestras e exposições internas e itinerantes, como na sede do Museu Histórico Nacional, no Instituto de Educação e na Associação Brasileira de Imprensa (Noticiário, 1969: 180). O Museu também participava dos eventos cívicos que foram uma das marcas do regime militar, sobretudo voltados para o público infanto-juvenil, integrando-se às comemorações oficiais dessas datas, como se pode observar na figura 1, em que ao fundo se vê o mencionado 'pavilhão'.

Mas a situação da Campanha de Defesa do Folclore Brasileiro foi ficando bastante precária. Em 1971 fora perdida a sede "por falta de recursos" (Nascimento, 1988:

\footnotetext{
${ }^{4}$ As relações de parceria e cooperação entre a Campanha de Defesa do Folclore Brasileiro e o antigo Instituto Joaquim Nabuco de Pesquisas Sociais, também podem explicar a nomeação de Aécio de Oliveira. Este vinha do Museu de Antropologia do IJNPS, criado no bojo do Movimento Folclórico.
} 
8). Na tentativa de driblar as dificuldades, realizavam-se pesquisas em parceria com outras instituições, publicava-se a Revista Brasileira de Folclore ${ }^{5}$, e apoiavamse as iniciativas voltadas para a criação de museus de folclore pelo Brasil afora.

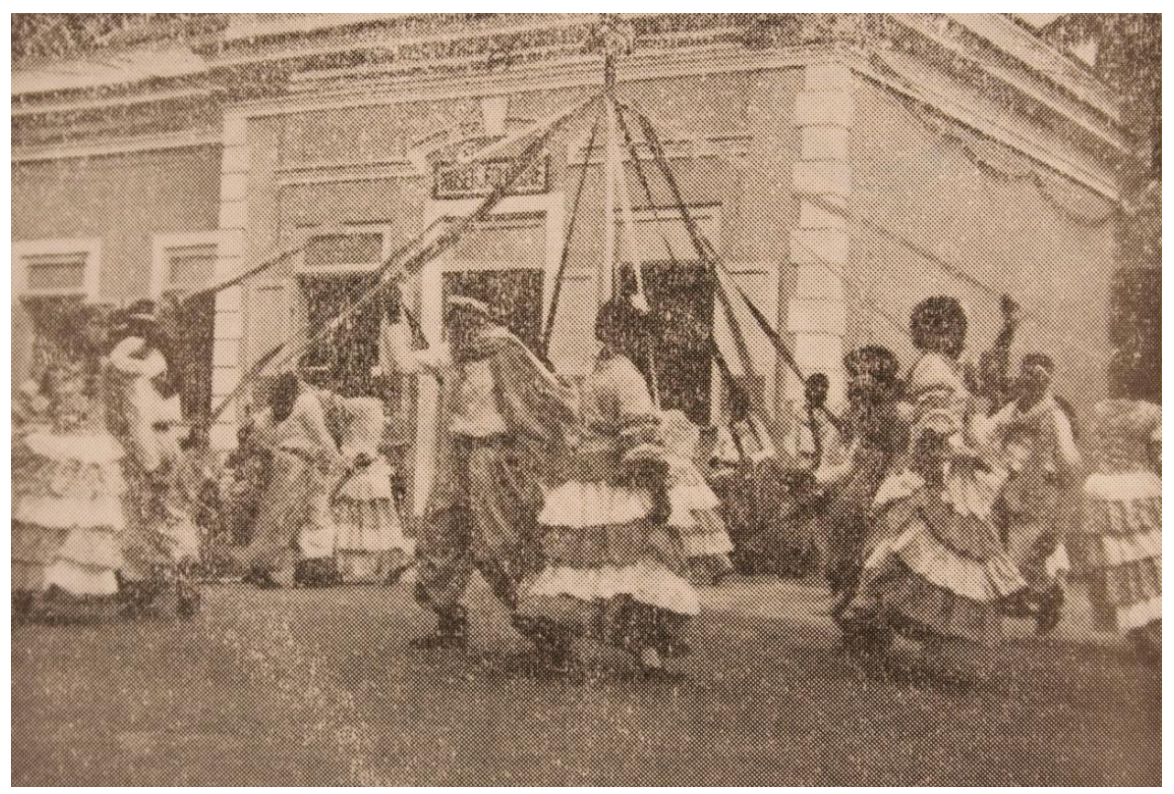

Figura 1 - Apresentação de dança de Pau de Fitas em frente ao Museu de Folclore, em comemoração ao 7 de setembro (Noticiário, 1970: 264)

A construção da memória do Movimento Folclórico Brasileiro e da Campanha de Defesa do Folclore Brasileiro percorreu vários caminhos e se utilizou de diversos instrumentos. Passou pela apropriação da noção de patrimônio, pela utilização da Revista Brasileira de Folclore como lugar de celebração da memória, e pela produção de farta documentação sobre os estudos de folclore, buscando construir no futuro a valorização do fato folclórico. À semelhança do que Chagas (2003: 144) designou de "vontade de formar e produzir continuidades", a concretização da "vontade de memória" do Movimento Folclórico Brasileiro passou sobretudo pelos museus. Exemplo disso encontra-se em uma das várias propostas de reformulação da Campanha, com vistas a uma mais sólida institucionalização, que aponta para o

\footnotetext{
${ }^{5}$ A Revista Brasileira de Folclore, editada duas ou três vezes por ano, era um importante canal de divulgação dos fatos e feitos do folclore.
} 
caráter imaterial de alguns aspectos da cultura, que só a partir de 2000 , com a edição do Decreto 3.551, que instituiu o registro de bens culturais de natureza imaterial, passa a ser considerado pelos órgãos de preservação do patrimônio cultural:

\begin{abstract}
Folclore não é visto apenas em Museus. Mas ninguém discute a importância desses órgãos e do acervo que neles, somente neles, devem ser guardados. [...] Sem museu não se estuda folclore, sobretudo num país de dimensão continental como o nosso, onde as áreas devem ser determinadas com atenção e o material classificado detalhadamente dividido em duas grandes seções: artística e utilitária, envolvendo também cultura material e espiritual ${ }^{6}$, cada qual com suas subdivisões necessárias (Proposta, [1972]).
\end{abstract}

A construção da memória institucional passou também pela negociação e por algumas concessões ao Estado autoritário, que lhe deu apoio enquanto interessaram as ações rumorosas da Campanha no sentido de uma reinterpretação das "categorias de nacional e do popular", que permitisse "concretizar a realização de uma identidade 'autenticamente brasileira'” através da ideologia da integração nacional (Ortiz, 1994: 130).

A questão do nacional e do popular é uma questão política que vem sendo reinterpretada a cada momento histórico pelos grupos sociais que conformam a nação (Ortiz, 1994: 8). Ortiz afirma que "existe uma história da identidade e da cultura brasileira que corresponde aos interesses dos diferentes grupos sociais na sua relação com o Estado" (Ortiz, 1994: 9). Os folcloristas perseguiam uma identidade nacional genuinamente brasileira, e o regime militar dos anos de chumbo trabalha a memória nacional como prolongamento da memória coletiva popular. Sendo assim, o projeto dos folcloristas, devidamente apropriado e reinterpretado pelo discurso do Estado corresponde então aos interesses do projeto militar.

\footnotetext{
${ }^{6}$ Grifo da autora.
} 
É o que Pollack (1989: 8-11) chama de enquadramento da memória, ações que buscam "manter a coesão interna e defender as fronteiras daquilo que um grupo tem em comum, em que se inclui o território". Esse trabalho de enquadramento tem limites impostos, tanto pelas circunstâncias quanto pelas regras internas do próprio grupo e, "além de uma produção de discursos organizados em torno de acontecimentos e de grandes personagens, os rastros desse trabalho de enquadramento são os objetos materiais: monumentos, museus, bibliotecas etc." (Pollack, 1989: 10-11).

Apesar dos museus construídos como rastros do enquadramento, o prestígio e a eficácia da estratégia da Campanha vão decaindo com o passar do tempo. A política para a cultura vai se mostrando insustentável na medida em que surgem os grupos e movimentos sociais que clamam por mais liberdade de ação. Os antigos estudiosos do folclore vão perdendo lugar com a morte e com a própria idade. Da mesma forma, na disputa de poder pela formação ideológica do nacional, já vinha de longe uma oposição às ideias dos folcloristas. Assim foi com Florestan Fernandes e a escola paulista de sociologia, que combatia o caráter conservador dos que consideravam o folclore como o saber tradicional, rotulando-o de atraso e retardamento cultural. Assim foi também com o ISEB (Instituto Superior de Estudos Brasileiros), que reuniu intelectuais de destaque na formação do pensamento social brasileiro ${ }^{7}$. Criado em 1955, com a finalidade de fundamentar ideologicamente a política nacional-desenvolvimentista do governo JK, propugnava que desenvolvimento econômico e social e fortalecimento da nacionalidade caminhavam juntos. Foi fechado pelas lideranças do golpe militar de 1964.

\footnotetext{
7 Como Anísio Teixeira, Ernesto Luís de Oliveira Júnior, Hélio Cabal, Hélio Jaguaribe, Roberto Campos, Roland Corbusier e Temístocles Cavalcanti.
} 
Outro movimento que fortaleceu o combate às ideias dos folcloristas foi o Centro de Cultura Popular (CPC), criado no âmbito da União Nacional dos Estudantes (UNE) em 1962, “como ação revolucionário-reformista definida dentro de quadros artísticos e culturais, alimentados pela ideologia nacionalista que transpassa a sociedade brasileira como um todo" à época (Ortiz, 1994: 69). Os CPCs criticavam e questionavam a concepção conservadora que dominou os estudos de folclore. Eles acreditavam no poder conscientizador e formador de opinião da arte e, sobretudo que "fora da arte política não há arte popular", acrescentando que era dever do homem brasileiro "entender urgentemente o mundo em que vive" para "romper os limites da presente situação material opressora" (Calicchio, 2011). O Conceito de cultura popular se confunde com o de conscientização, como função política. 0 intelectual deve organizar a cultura, "tornando-se povo" (Ortiz, 1994: 71-72). Seu objetivo era atingir as massas, levando a intelectualidade a com elas interagir no sentido da "desalienação da cultura"8. Nos primeiros dias seguintes ao golpe militar, a UNE foi incendiada e todos os CPCs fechados.

A estratégia da Campanha, embora desgastada, sai vitoriosa, e a institucionalização tão almejada vem com a saída de Renato Almeida em 1974, quando o também folclorista Bráulio do Nascimento assume seu lugar na direção executiva da Campanha de Defesa do Folclore Brasileiro, a convite de Manuel Diégues Júnior, que assumiu o Departamento de Assuntos Culturais (DAC) do Ministério da Educação e Cultura.

A Campanha prosseguia sob os cuidados dos folcloristas e, desse modo tinha continuidade o projeto do Movimento Folclórico Brasileiro. A gestão de Bráulio do Nascimento caracteriza-se por uma estratégia de fortalecimento, para levar a Campanha a recuperar “o tempo perdido” (Nascimento, 1988: 8).

\footnotetext{
${ }^{8}$ A proposta do CPC atraiu artistas e intelectuais, entre os quais Ferreira Gullar, Francisco de Assis, Paulo Pontes, Armando Costa, Carlos Lira e João das Neves.
} 
A partir de 1975 a ação governamental na área da cultura se intensifica. Elabora-se o Plano Nacional de Cultura - "primeiro documento ideológico que um governo brasileiro produz e que pretende dar os princípios que orientariam uma política de cultura" - e são criados os principais órgãos da área cultural, como a EMBRAFILME, a Pró-Memória e a FUNARTE (Ortiz, 1994: 85-86). E museus, muitos museus, dentre eles os de folclore.

\begin{abstract}
Popular significa tradicional, e se identifica com as manifestações culturais das classes populares, que em princípio preservariam uma cultura "milenar", romanticamente idealizada pelos folcloristas. Dentro dessa perspectiva, o popular é visto como objeto que deve ser conservado em museus, livros e casas de cultura, alimentando o saber nostálgico dos intelectuais tradicionais (Ortiz, 2001: 160).
\end{abstract}

A ação, agora com maior apoio do governo, é mais ostensiva. Aqui é possível perceber como as ligações pessoais dos intelectuais brasileiros com a política ajudaram a conduzir os rumos da cultura no país (Miceli, 1979), e de como o governo continuava se valendo de intelectuais de destaque em seus campos de atuação para executar sua política de cultura. A intervenção pessoal do folclorista Manuel Diégues Júnior à frente do Departamento de Assuntos Culturais do Ministério da Educação e Cultura consolida a institucionalização da Campanha9. Diégues transfere pela portaria número 235, de 21 de novembro de 1974, o antigo prédio da Casa da Guarda presidencial, para sede da Campanha, que próxima ao seu Museu de Folclore, ganha maior visibilidade.

O período de obras de restauração e adaptação às novas funções foi de intensa realização de exposições externas e itinerantes, e enquanto acontecia a reforma, o

\footnotetext{
${ }^{9}$ Aqui vale lembrar que Diégues fez parte do Movimento Folclórico Brasileiro e "juntamente com Renato Almeida [...], Edison Carneiro, Joaquim Ribeiro e Simeão Leal [compôs] a Comissão que elaborou o projeto de Lei de criação da Campanha e de seu regulamento" (Nascimento, 1974: 1).
} 
Museu de Folclore permaneceu instalado em dependências do Museu da República. Na nova sede foi montada uma exposição de longa duração (figura 2).

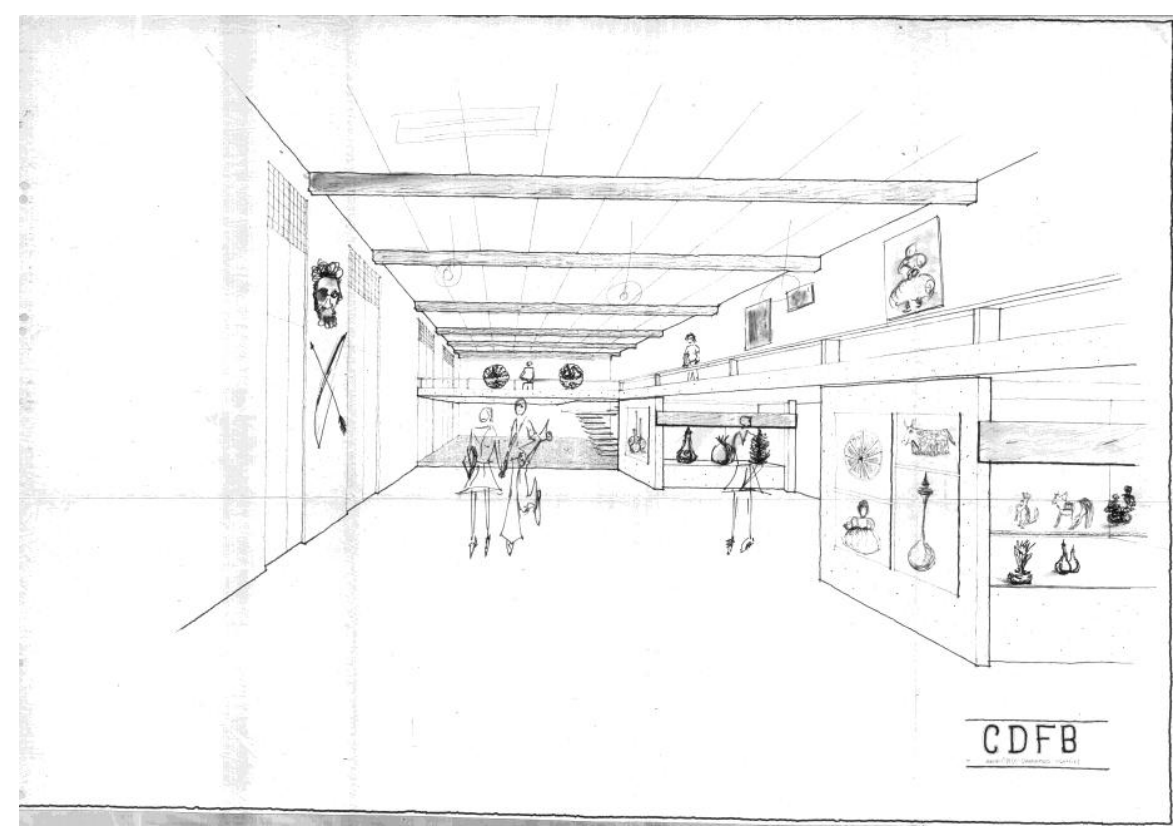

Figura 2 - Croqui da exposição permanente de 1975. Desenhista: não identificado. Acervo CNFCP

Contudo, as obras de construção do Metrô do Rio de Janeiro causam danos à estrutura recém reformada e inaugurada, e o prédio teve que ser fechado em sua maior parte para nova reforma que durou quase três anos, entre negociações e obras propriamente ditas. E novamente foram feitas exposições, muitas exposições... "no museu, [...] na Gulbenkian, [...] na própria Funarte, [...] na Biblioteca Nacional, na sessão de Música" (Nascimento, 1988: 21).

Em 1976 a Campanha foi incorporada à FUNARTE, alcançando sua institucionalização. Nesse mesmo ano, através da Lei 6.353, de 13 de julho, a denominação do Museu é alterada para Museu de Folclore Edison Carneiro, em homenagem ao segundo diretor-executivo da Campanha, que havia falecido quatro anos antes. 
A sede da Campanha estava fechada para obras e o acervo do Museu de Folclore Edison Carneiro crescia, necessitando de mais espaço. Celia Corsino (2007), que dirigiu o Museu de 1978 a 1982, frisa que o Museu "não tinha uma área de exposição permanente, somente um depósito de objetos [e vivia] de exposições temporárias em diversos lugares". 0 acervo do Museu ocupava duas pequenas salas nos fundos do prédio da Campanha, mas a equipe organizava exposições itinerantes em vários locais e "com os temas mais diferentes possíveis e sempre com o acervo do museu", o que segundo Ferreira (2010: 3) "foi fundamental para que [o Museu] tivesse conseguido aquele espaço [da antiga garagem do Palácio], porque o museu estava sempre mostrando acervo, serviço, vontade". Por isso a documentação do acervo museológico tomou grande impulso nessa fase. 0 acervo crescia e, mesmo restritos a um espaço de reduzidas dimensões e quase impróprio às atividades técnicas, os funcionários e estagiários que atuavam no Museu, voltaram-se para aprimorar a técnica de documentação do acervo. A interferência de Diégues também é decisiva para a aquisição da antiga garagem e instalação da primeira exposição de longa duração do Museu de Folclore Edison Carneiro em espaço próprio, inaugurada em 14 de março de 1980. Ali também foi instalada a área de trabalho dos técnicos, aí incluído um laboratório de conservação e restauro.

Quando o folclore e a cultura popular passam a integrar a estrutura da Fundação Nacional de Arte (FUNARTE), e o Museu é transferido para a antiga garagem do Palácio do Catete, local de grande visibilidade dentro do Parque, a arte popular reunida e preservada pela Campanha, vem ocupar o mesmo espaço institucional e, simbolicamente, o mesmo patamar das chamadas artes plásticas e eruditas.

Sobre a questão do espaço, Halbwachs (1952: 143) afirma que "não há memória coletiva que não se desenvolva num quadro espacial", por ser o espaço uma "realidade que dura" e que está presente em todas as atividades humanas. 0 espaço não é suficiente, mas é condição necessária para a construção e 
reconstrução da memória. Isso parece explicar a preocupação de indivíduos e instituições, quanto à delimitação de seu lugar no território. E de fato, só quando adquire seu espaço físico em definitivo, ao lado da institucionalização, é que a Campanha de Defesa do Folclore Brasileiro e o Museu de Folclore ganham efetivamente seu espaço social e simbólico no imaginário popular. A partir de então, como Instituto Nacional do Folclore (INF), consagrou-se nas instâncias de estudo e disseminação da cultura popular, tanto no cenário nacional quanto no internacional.

A exposição de 1980 organizou-se nos seguintes núcleos temáticos: Lúdica Infantil, Medicina Popular, Danças e Folguedos, Instrumentos Musicais, Literatura de Cordel, Religiosidade Popular e Artesanato. Esta exposição ganhou um volume da Coleção Museus Brasileiros, edição da FUNARTE (figura 3).

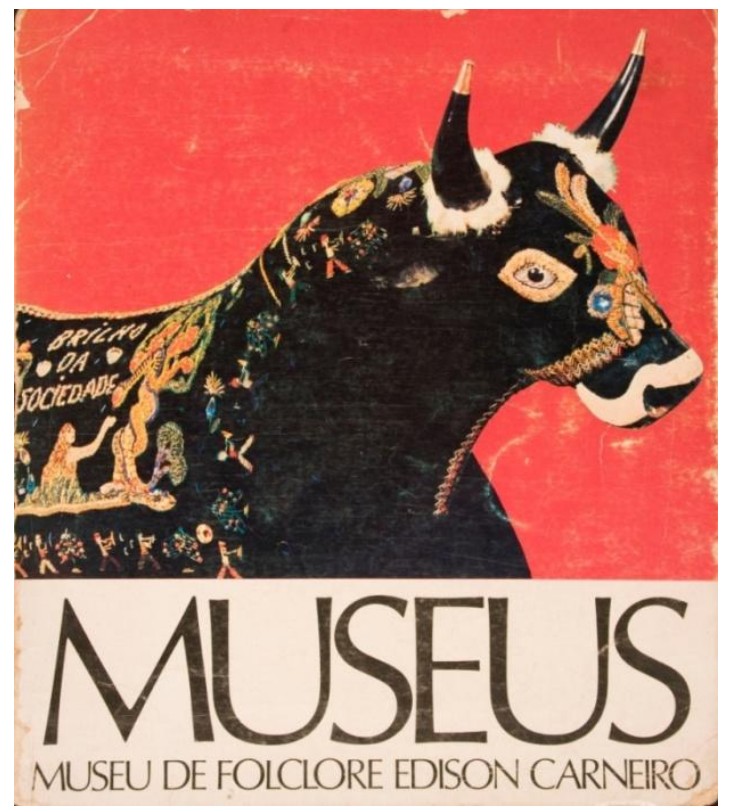

Figura 3 - Capa do volume 5 da Coleção Museus Brasileiros (FUNARTE, 1981). Fotógrafo: Francisco Moreira da Costa. Acervo da autora.

Esta publicação, além da consagração do antigo 'Patinho Feio', representa o reconhecimento do acervo de cunho popular como expressão artística, e prenuncia 
as mudanças no terreno cultural introduzidas por Aloísio Magalhães na Secretaria de Cultura do MEC, que naturalmente vão se refletir no Instituto Nacional de Folclore.

No tocante à Museologia, as informações continuam apontando para um Museu que se valia muito da mão de obra dos estagiários de Museologia, interessados na aplicação prática das técnicas aprendidas. A tradição do período anterior, de território aberto aos estudantes de Museologia, vinha se repetindo. Daí a realização de muitas exposições temporárias e itinerantes, e nessa época, as atividades educativas e culturais ganharam grande impulso, inclusive com ações consideradas "de ponta [na época] como o atendimento a deficientes principalmente de síndrome de Down"(Corsino, 2010: 4). A presença de estudantes, com o idealismo, o destemor e o vigor próprios da juventude, fazia com que o Museu fosse um espaço privilegiado de liberdade e experimentação.

A exposição de 1980 pode ser tomada como exemplo dessa liberdade de experimentação, em que o Museu inovou em termos expográficos, com a exposição de objetos museológicos fora de vitrines. Com certeza uma ousadia, em momento de ousadias e questionamentos no território museal, mas em tempos ainda marcados pela predominância dos cânones museológicos da tradição barroseana. Nessa exposição também foi ensaiada alguma contextualização de objetos e a utilização de materiais um tanto inusitados, como seixos e barro no fundo de vitrines, numa tentativa de "aquecer" a frieza do mobiliário de fórmica (Ferreira, 2010: 8).

O apuro técnico foi a marca desse período, e novas experimentações foram sendo feitas também no campo da conservação, como o uso de sílica-gel no fundo vitrines para retirar o excesso de umidade. 0 empenho no aperfeiçoamento da documentação também se impôs porque o fazer museal relativo aos objetos começava a evidenciar que quando era preciso recorrer à documentação para 
fundamentar ações educativas e elaborar exposições que não fossem simples mostruário de objetos, faltavam informações básicas, como material, técnica, data de fatura, o contexto em que foi produzido e o histórico do objeto.

No campo da política, a partir de 1975, o país entra na fase de redemocratização, na "chamada distensão" do governo Geisel, em resposta às exigências sociais de liberdade e direitos civis, pois "predominavam movimentos sociais que visavam à ampliação do espaço de discussão e dos centros de decisão nas instituições públicas e privadas" (Chauí, 1989: 50-53). 0 projeto estatal de liberdade vigiada pode explicar o retorno de Bráulio do Nascimento à cena institucional, e a nomeação de Manuel Diégues Júnior, um dos mais influentes membros do Movimento Folclórico Brasileiro, para o Departamento de Assuntos Culturais do Ministério da Educação e Cultura.

A postura institucional, de adaptação à nova conjuntura, demonstrando o "conformismo", por um lado, e a "resistência", por outro (Chauí, 1989), puderam preencher as brechas que eram deixadas pelo regime ditatorial, que foi se apropriando da cultura popular em nome da identidade nacional, que desde sempre perseguiu o ideário folclorista. Assim, os lugares de memória puderam proliferar-se, como sonhavam os folcloristas, e como interessava aos representantes do regime militar, para promover a propalada "integração nacional" pelo estímulo controlado à cultura popular.

Bráulio do Nascimento deixa a direção-executiva do Instituto Nacional do Folclore em 1982, após uma gestão que foi marcada pelo fortalecimento e projeção do Instituto Nacional do Folclore em nível nacional, e pela consolidação do Museu de Folclore Edison Carneiro. Sua saída significou também o encerramento da era folclorista na condução dos destinos da Instituição, dando lugar à Antropologia e à política do patrimônio cultural. 
A política governamental para a cultura seguia sob nova orientação. Os intelectuais conservadores são substituídos por intelectuais mais jovens com perfil mais executivo, "aquele que representa a possibilidade real de consolidação de uma organicidade política e ideológica: os administradores" (Ortiz, 1989: 108). Aloísio Magalhães é um profissional com tal perfil e assume a Secretaria de Assuntos Culturais do Ministério da Educação e Cultura em 1979.

A novidade desse período é que no plano trienal para a educação e cultura, apresentado pelo MEC em 1982, pela primeira vez desde 1964, “a Cultura Popular foi incorporada oficialmente ao projeto estatal". Novos termos são incorporados ao texto oficial, como 'comunidade', 'participação comunitária', 'criatividade', entre outros absorvidos do jargão da oposição e da Teologia da Libertação (Chauí, 1989: 88-89).

Sinalizava-se, já, para o uso do conceito antropológico de cultura nas políticas de patrimônio, e que viriam a sedimentar-se anos mais tarde. A atualização do conceito resulta na ampliação dos conceitos de bem cultural e de patrimônio cultural $^{10}$, e que na Museologia vinha se impondo desde a Mesa Redonda de Santiago do Chile em 1972. Conceitos como identidade nacional e fato folclórico ${ }^{11}$ deixam de ser o centro das atenções. A memória e o patrimônio reinam soberanos a partir de então.

A política de "patrimônio" adquire uma nova dimensão. Calcada na noção antropológica de cultura, desloca-se da aceitação de um produto único, de valor "excepcional", e passa a ser pensada como um processo, um

\footnotetext{
10 Esse processo só vem a explicitar-se na Constituição de 1988, que em seu capítulo III, Seção II, artigo 216, define patrimônio cultural (Brasil, 1988: 35), e só se constitui, reconhece e atribui novas dimensões ao patrimônio cultural com a edição do Decreto 3551, em 2000.

${ }^{11}$ A Carta do Folclore Brasileiro (1951) estabeleceu que "constituem o fato folclórico as maneiras de pensar, sentir e agir de um povo, preservado pela tradição popular e pela imitação e que não sejam diretamente influenciadas pelos círculos eruditos e instituições que se dedicam ou à renovação e conservação do patrimônio científico e artístico humano ou à fixação de uma orientação religiosa e filosófica".
} 
ressignificar-se, um fazer-se a cada modalidade de interação, a cada configuração de posições e a cada contexto histórico (Simão, 2003: 59)

Nesse cenário Aloísio Magalhães foi um dos atores principais. Empresário, designer gráfico e artista plástico renomado, com trânsito e experiência na esfera pública, é incontestavelmente um dos grandes nomes na política de patrimônio, inaugurando a fase 'moderna' do SPHAN, assim como o fez Rodrigo Melo Franco de Andrade, na chamada "fase heróica" do órgão de preservação (Ortiz, 1989: 124 e Simão, 2003: 60). Sua atuação não se pautou pela procura da identidade nacional, mas centrou-se nas discussões em torno da diversidade cultural característica dessa identidade, procurando integrar o patrimônio edificado, ou de "pedra e cal", com a pluralidade das manifestações culturais, sobretudo da cultura popular.

Por essa nova ótica "administrativa", difusão e consumo passam a ser definidores da política cultural. Em tempos de movimentos sociais cada vez mais fortes, o acesso à cultura adquire significado de democratização, e nesse contexto, a quantidade importa mais que a qualidade. 0 consumo está associado à capacidade de "vender" cultura, transformando os bens da União, assim como os produtos da cultura popular, em "bens rentáveis", trazendo com isso, tanto dividendos aos cofres públicos, quanto melhores condições de subsistência às comunidades mais pobres. A Secretaria de Assuntos Culturais do MEC, de Aloísio, "define durante este período duas linhas mestras de sua política: a institucional e a comunitária". A institucional voltava-se principalmente para a promoção de eventos e a comunitária, visava garantir mercado para as produções populares (Ortiz, 1989: 119).

Ortiz levanta duas hipóteses prováveis para essa política cultural voltada para o consumo e a rentabilidade dos bens culturais. A primeira seria consequência do momento de crise econômica. A cultura, que nunca foi prioridade, passa para 
segundo plano, seguindo a educação e a saúde, áreas historicamente menos favorecidas no orçamento da União, derivando daí a redução orçamentária e a preocupação com a rentabilidade dos equipamentos culturais. A outra hipótese baseia-se na ascensão dos movimentos sociais, cada vez mais fortes e reivindicativos na luta pela liberdade política e por melhores condições de vida. Em sua ação cultural voltada para a vida comunitária, o Estado busca envolver as lideranças das "comunidades de base".

Uma política cultural comunitária proporcionaria ao Estado a possibilidade de intervir numa esfera da vida social sem abrir mão de sua política econômica recessiva. A valorização da chamada cultura de subsistência não seria um passo possível nessa direção? (Ortiz, 1989:

Sem dúvida, o envolvimento das lideranças comunitárias possibilitaria ao "Estado autoritário [...] não só absorver as manifestações populares (cultura e esporte), mas sobretudo 'controlá-las' enquanto seu promotor". 0 interesse em deixar de ser apenas incentivador, como no pós 1964, para ser promotor da cultura popular, "surgiu à medida que se desenvolviam movimentos sociais populares de oposição, tornando-se necessário contê-los" (Chauí, 1989: 88-89).

Os novos rumos dados ao Instituto Nacional do Folclore correspondem à mudança da política cultural como um todo, que já começava a impor-se, e vem expressa na fala de Aloísio Magalhães, em 1980.

Ocorre, entretanto, que o conceito de bem cultural no Brasil continua restrito aos bens móveis e imóveis, contendo ou não valor criativo próprio, impregnados de valor histórico essencialmente voltados para o passado, ou aos bens da criação individual espontânea, obras que constituem o nosso acervo artístico [...] quase sempre de apreciação elitista. Aos primeiros deve-se garantir a proteção que merecem e a possibilidade de difusão que os torne amplamente conhecidos. [...] 
quanto aos segundos, basta assegurar-lhes a liberdade de expressão e os recursos necessários à sua concretização. [...] Permeando essas duas categorias, existe vasta gama de bens - procedentes sobretudo do fazer popular - que, por estarem inseridos na dinâmica viva do cotidiano, não são considerados bens culturais nem utilizados na formulação das políticas econômica e tecnológica (MAGALHÃES, 1985: 52-53 apud FONSECA, 2003: 67).

Por indicação de Aloísio, Lélia Coelho Frota (1938 - 2010) assume a direção do Instituto Nacional de Folclore em 1982. Poeta, antropóloga, historiadora e crítica de arte, Lélia diplomou-se em Museologia em 1964, após usufruir de uma bolsa do governo francês para estagiar no Museu de Artes e Tradições Populares, criado em Paris por George Henri Rivière, e onde travou conhecimento com o Museu do Homem, idealizado e criado por Paul Rivet. Dentre os cargos que ocupou, destacase a presidência do Instituto do Patrimônio Histórico e Artístico Nacional (IPHAN). Dedicou-se aos estudos de cultura popular, tendo se tornado uma das suas maiores especialistas (Sá, 2007: 139 e 169).

Apesar de curta, a gestão de Lélia até hoje é considerada um grande marco na trajetória institucional. Esse é um período em que se operou uma grande mudança conceitual na Instituição, que passa por uma revisão geral de suas concepções museológicas e museográficas, pela introdução de novos projetos e pela incorporação de novos profissionais, agora empenhados em cunhar uma feição mais antropológica ao Museu. Com isso, reaproximando o Instituto Nacional do Folclore das universidades e centros de pesquisa ${ }^{12}$, de que se afastara desde que o estudo do folclore havia perdido toda a legitimidade junto a essas instituições.

Para Mendonça (2008: 19-20), em sua análise do período de Lélia, as ações desenvolvidas pelo Instituto foram submetidas "a um processo de reconceituação

12 Vilhena (1997: 28) aponta em seu trabalho que em diversos momentos, os folcloristas participaram intensamente dos debates que definiram a constituição do campo das ciências sociais no Brasil. 
[que] implicou numa ruptura com os modelos conceituais adotados pelos folcloristas e a introdução da categoria cultura popular, adotada pela antropologia". Ao trazer para o INF a nova postura do governo para a cultura, Lélia Coelho Frota elege o Museu de Folclore Edison Carneiro como ponta de lança da sua atuação, e "aposta na transformação do Museu como o grande emblema da transformação da mudança de abordagem conceitual do Instituto", e palco privilegiado para mostrar o novo discurso do Instituto Nacional do Folclore (Ferreira, 2007: 15), por sua comunicação direta com o público. Ricardo Gomes Lima (2008: 12), que veio para a Instituição trazido por Lélia, lembra que "o Museu aparecia para ela como campo vasto, [que ela queria semear] e ao mesmo tempo, um campo estratégico para refletir assim, a cara dessa mudança institucional".

A nova direção do INF fortalece ainda mais o Museu de Folclore Edison Carneiro, criando ali a divisão de Antropologia, que introduzia a moderna pesquisa etnográfica em suas atividades, no intento de dar-lhe mais cientificidade. Note-se que até então o Museu respondia pelas atividades de preservação do acervo, de elaboração e montagem de exposições, e pelas ações educativas. Lélia promoveu com isso a aproximação dos profissionais do Museu com os núcleos de pesquisa já existentes no Instituto Nacional do Folclore.

Com Lélia o termo folclore é praticamente banido do discurso oficial (Ferreira, 2010: 15). O termo só é utilizado quando se refere a programas e projetos do passado. Quando se refere ao presente, as expressões são cultura popular, cultura material, arte popular etc. A política institucional, agora trabalhando com o novo conceito de cultura em voga entre as ciências sociais fortalecidas, distancia-se do folclore e de suas instâncias estaduais, as comissões de folclore.

A reformulação da exposição de longa duração foi a linguagem escolhida para transmitir ao público a mudança de postura e o realinhamento institucional, 
sugerindo o papel atribuído ao Museu, de veículo e vitrine das novas ideias. É comprado o imóvel contíguo à sede do Instituto Nacional de Folclore. A direção inicia o movimento interno de mudanças e o Museu é um dos principais instrumentos utilizados para operacionalização e divulgação dessa mudança. Através de um processo, que durou dois anos, de restauração e adaptação, e de elaboração e montagem de outra proposta expográfica, o prédio recém-adquirido é ocupado com a nova exposição de longa duração.

Essa exposição de longa duração ${ }^{13}$, inaugurada a 10 de agosto de 1984 , consistia de quatro grandes módulos temáticos: Ritos de Passagem (nascimento, casamento e morte), 0 Mundo Ritualizado das Festas, 0 Homem na Transformação da Natureza e na Produção da Cultura, e Indivíduo e Coletividade. Em exposição estavam 400 obras, e nessa época o acervo já atingia a marca dos 10 mil itens. De partida, o longo discurso de Lélia na cerimônia de inauguração, é bastante elucidativo como narrativa de sua gestão. Esse discurso é quase um relatório, já que em seguida, ela se afasta da direção. Sua fala aponta para o papel do Museu no contexto das novas diretrizes, e expressa suas preocupações museais, que naquele momento especial espelhava as preocupações da equipe do Museu e da comunidade museológica empenhada em mudanças. No Brasil, a classe lutava pela regulamentação da profissão e no mundo nascia o movimento da Nova Museologia.

Ao abrir sua fala, Lélia Coelho Frota situa o Museu de Folclore Edison Carneiro como parte do "corpo vivo" do Instituto Nacional de Folclore e cita como objetivos "o entendimento, registro, apoio, divulgação e restituição às fontes das diversas manifestações de cultura popular em nosso país" (Frota, 1984: 1). Esclarece que o

\footnotetext{
${ }^{13}$ A dissertação defendida em 2007 por Rita Gama, com o título "Quantos folclore brasileiros? As exposições permanentes do Museu de Folclore Edison Carneiro em perspectiva comparada"; e a tese de doutorado de Elisabete Mendonça: "Tesauro e exposições permanentes de folclore e cultura popular: narrativas sobre arte popular elaboradas pelo Centro Nacional de Folclore e Cultura Popular (1980-2004[2006])" defendida na Escola de Belas Artes da UFRJ, em 2008, são alguns exemplos de pesquisas feitas tendo as exposições do Museu de Folclore Edison Carneiro como tema.
} 
objetivo primordial é o "entendimento do homem brasileiro", considerando a pluralidade da identidade cultural brasileira.

Mais adiante, ela parece fazer questão de negar o distanciamento e a ruptura das ideias mestras sob as quais nasceu a Campanha de Defesa do Folclore Brasileiro, quando afirma que obedece “à precisa recomendação da Carta do Folclore de 1951, que entende a nossa matéria como integrante das ciências antropológicas e culturais" (Frota, 1984: 2). Nessa fala e no Seminário realizado para apresentar e discutir a nova exposição do Museu de Folclore, Lélia torna visível a preocupação em enfatizar a continuidade de uma ação, mais do que as rupturas. E segue citando outros pontos da Carta e alguns "ilustres antecessores", como Cecília Meirelles, Edison Carneiro, Câmara Cascudo. Ela frisa também a "permanente preocupação de integrar instituições e valores locais nos Estados [e municípios] com a ação federal" (Frota, 1984: 2-3). Após esse preâmbulo ela sintetiza o significado do Museu (e o grifo é dela) já fazendo menção ao papel social assumido pelo Museu, que já integrava o discurso do Estado, e já vinha freqüentando as discussões e questionamentos do campo museológico desde a década de 1970, quando se iniciaram as inquietações em torno da função social do museu e da Museologia.

\footnotetext{
Penso, portanto ter procurado deixar claro o que, para nós, é o significado do Museu de Folclore Edison Carneiro: o de um instrumento científico, educacional e divulgador, em diversos níveis, do fazer do homem brasileiro, no sentido de suscitar, dentro de nossas possibilidades, uma maior solidariedade social. (Frota, 1984: 3)
}

Lélia assinala que na proposta da exposição que se inaugura, o homem brasileiro é "compreendido em seus variadíssimos contextos sócio-culturais, dentro do pluralismo que constitui a maior riqueza e fonte da nossa identidade cultural". 0 foco deixa de ser o fato folclórico e muda para o homem, o produtor desse fato; a 
pluralidade substitui a tradição que traduz unidade nacional; a visão agora admite múltiplas leituras ou 'traduções' (Frota, 1984: 1).

No que tange à Museologia, não se trata mais de uma exposição sobre o objeto, mas sobre o homem, ator e produtor de cultura. O texto de abertura da exposição aponta para o novo partido teórico conceitual adotado, que "apresenta objetos/documentos que significam a visão de mundo e as formas de viver e relacionar-se de brasileiros pertencentes às mais diversas áreas culturais do país" e que são expressões materiais de algo que "continua vivo e se transformando lá fora, no contexto sociocultural onde os homens e as mulheres lhe dão vida e significado" (Instituto, 1982: 8-9).

A proposta conceitual da exposição trazia agora a maioria dos objetos fora de vitrines. No módulo "O Mundo Ritualizado das Festas", a nova proposta "abre um espaço para o carnaval, tema antes considerado pela instituição como fora dos seus limites de atuação. Este tema é também um exemplo da busca pela contemporaneidade da cultura popular" (Mendonça, 2008: 76). Tema que também pode servir de exemplo da "preocupação de 'desnordestinizar' a imagem corrente do folclore junto ao público" (Silva, 2008: 125). Preocupação que se percebe em todas as áreas de ação, desde a documentação, até as ações educativas e de difusão cultural.

O Museu de Folclore Edison Carneiro, adquire cada vez maior visibilidade. Seu corpo funcional, sobretudo os museólogos, passa a vê-lo para além de um simples repositório da cultura material, e procuram formas de apresentar o acervo em exposição como testemunho de contextos sócio-econômico-culturais, como resultado da experiência do viver. Com isso busca atualizar-se nos métodos de documentação, conservação e exposição. O Seminário realizado em 1984 para apresentar a nova concepção da exposição de longa duração, dá amplo destaque às mudanças na técnica aplicada à preservação do acervo, especialmente no 
tratamento documental do acervo, que incorpora os novos recursos de som e imagem, e tem como propósito uma contextualização do objeto (Ferreira, 1984: 5). Da mesma forma que narra os avanços no uso de técnicas de conservação, uma grande preocupação da Museologia no período.

Em sua fala, Lélia dá conta do quanto o Instituto Nacional de Folclore se engajou e participou da política cultural traçada pelo Estado. Ela aponta como "uma das principais preocupações não só deste Instituto como da própria Secretaria da Cultura [...] a questão da produção de artesanato e da identidade cultural" (Frota, 1984: 4) e narra a realização de Seminário sob a coordenação do Núcleo de Cultura Material do Instituto Nacional de Folclore, que chegou ao seguinte "consenso sobre a matéria: a elevação da qualidade de vida não pode ser dissociada das identidades culturais específicas dos grupos e indivíduos que produzem artesanato" (Frota, 1984: 4-5). Lélia discorre que a partir das recomendações oriundas desse Seminário também é criado o projeto Sala do Artista Popular (de 1983), "um espaço de frente de rua no Instituto Nacional do Folclore à disposição de grupos e indivíduos produtores de cultura popular - para que aí tenham a oportunidade de comercializar livremente o que fazem - sem separar o produtor do seu produto" (Frota, 1984: 4). Desde então a Sala do Artista Popular (SAP) é um programa que além das exposições temporárias onde se exibe a produção de artistas e comunidades artesanais situadas em seus contextos, e são disseminados os estudos do Centro, destina-se também à divulgação e escoamento da produção artesanal e artística popular.

No que diz respeito ao Museu de Folclore Edison Carneiro especificamente, é importante mencionar que nesse período a forma e a política de aquisição de acervo também sofreram um processo de transformação. A aquisição voltou-se para o preenchimento de lacunas percebidas no acervo, numa relação direta com o que se considerou representativo da cultura popular brasileira. Tinha também o intuito de coletar acervo que viria compor a exposição de longa duração, 
inaugurada em 1984. Tendo isso em vista, os profissionais do Museu passaram a preocupar-se com a "programação da aquisição de acervo" (Ferreira, 1984: 5-7), com base em critérios definidos de maneira mais formal. Como fruto dessa fase foi elaborado o documento "Critérios de incorporação e empréstimo de objetos", que se pautou na legislação básica da FUNARTE, nos textos da Associação Brasileira de Museologia (ABM) e no documento "Ética de Aquisições", do ICOM, entre outras publicações disponíveis à época. Este documento constitui-se num registro da preocupação do corpo técnico do Museu com o estabelecimento de uma política norteadora da formação de seu acervo baseada em critérios mais técnicos, prevendo até a recusa de objetos sem a devida documentação, que viessem a causar interferência ou desvalorização das manifestações populares, ou cuja doação estivesse condicionada a situações especiais de guarda ou exposição. Além disso, nessa fase se estabelece a rotina de aquisição de obras a cada nova exposição na Sala do Artista Popular, para incorporação ao acervo do Museu de Folclore Edison Carneiro. Considerando que o programa SAP já possui mais de vinte e cinco anos de atuação ininterrupta, sua importância social e econômica para o artista popular tem sido evidenciada e sua contribuição para a formação do acervo do Museu, considerável.

No mesmo ano de inauguração da nova exposição, Lélia Coelho Frota deixa a direção do Instituto Nacional de Folclore ${ }^{14}$. Apesar da breve permanência à frente do INF, a narrativa institucional desde então vem repetindo que sua influência perdura nas ações do órgão, pelo menos até a inauguração da próxima exposição de longa duração (Lima, 2008: 8), em 27 de dezembro de 199415. As novas tendências apontadas pela Nova Museologia foram também preponderantes nessa permanência das ideias da museóloga Lélia Coelho Frota.

\footnotetext{
${ }^{14}$ Aloísio Magalhães que, à frente da Secretaria de Assuntos Culturais do MEC, havia indicado a museóloga e antropóloga para a direção do Instituto Nacional do Folclore, morre em Pádua, na Itália, em 1982, quando tomava posse como presidente da Reunião de Ministros da Cultura dos Países Latinos.

${ }^{15}$ Exposição ainda em cartaz por ocasião da elaboração deste texto.
} 
Memória é construção, que envolve escolhas e disputas de diferentes grupos por diferentes memórias, em diferentes tempos. Assim vão-se construindo camadas de memórias que tendem a realçar determinadas lembranças e, igualmente, a apagar outras tantas. Para que uma determinada vontade de memória prevaleça há que prevalecer uma outra vontade, a vontade de esquecimento. A memória em sua construção exige que essas camadas sejam articuladas e discutam entre si. Nesta breve reconstrução da memória do Museu de Folclore Edison Carneiro, enfocando parte de sua trajetória, algumas camadas dessa memória foram reviradas e articuladas, na tentativa de resgatar algumas lembranças, talvez veladas por vontades de esquecimento.

\section{REFERÊNCIAS}

ABREU, Regina. A emergência do patrimônio genético e a nova configuração do campo do patrimônio. In: ABREU, R. e CHAGAS, M. Memória e patrimônio: ensaios contemporâneos. Rio de Janeiro> DP\&A, 2003, p.30-45. 72.

. Por um museu de cultura popular. Ciência em Museus. Belém: MPEG, v. 2, 1990, p. 61-

ALMEIDA, Renato. Discurso na Inauguração do Museu de Folclore. Rio de Janeiro: CDFB, 1968. 3 p. datilografadas.

ANASTASSAKIS, Zoy. Um projeto de design nacional: Aloísio Magalhães e o Centro Nacional de Referência Cultural. In: Congresso Brasileiro de Pesquisa e Desenvolvimento em Design, 8, 2008, São Paulo, SP. Anais...São Paulo: AEND/Brasil, 2008. p. 536- 544.

BRASIL. Constituição da República Federativa do Brasil. Brasília, DF, 1988. Disponível em <http://www.planalto.gov.br/ccivil 03/constituicao/constitui\%C3\%A7ao.htm> Acesso em 2 mar. 2009.

CALICCHIO, Vera. Centro Popular de Cultura (CPC) - verbete. Rio de Janeiro: Fundação Getúlio Vargas/CPDOC. Disponível em <http://www.fgv.br/CPDOC/BUSCA/Busca/BuscaConsultar.aspx> Acesso em: 20 jan. 2011.

CARVALHO, Wilma Thereza Rodrigues de. Relatório. Rio de Janeiro: CDFB/MEC, jan. 1971. $7 \mathrm{p}$. 
CHAGAS, Mario. Imaginação museal: Museu, Memória e Poder em Gustavo Barroso, Gilberto Freyre e Darcy Ribeiro. Tese (Doutorado em Ciências Sociais), Programa de Pós-graduação em Ciências Sociais, da Universidade do Estado do Rio de Janeiro (UERJ), Rio de Janeiro, 2003.

CHAUÍ, Marilena. Conformismo e Resistência: aspectos da cultura popular no Brasil. São Paulo: Brasiliense, 1989. 179 p.

CHOAY, Françoise. A alegoria do patrimônio. São Paulo: Estação Liberdade/UNESP, 2001.

CORSINO, Celia. Entrevista [mensagem pessoal]. Mensagem recebida por <vaniadolores@oi.com.br > em 10 nov. 2010.

CORSINO, Celia. Entrevista [mensagem pessoal]. Mensagem recebida por < vaniadolores@oi.com.br>em 25 jan. 2011.

DUARTE, Luiz Fernando Dias. Memória e reflexividade na cultura ocidental. In: ABREU, R. e CHAGAS, M. (orgs.). Memória e patrimônio: ensaios contemporâneos. Rio de Janeiro, DP\&A, 2003, p. 305-316.

ESPECIALISTA diz que museu é verdadeiro laboratório de civilizações humanas. Diário de Pernambuco. Recife, 10 out. 1969.

FERREIRA, Claudia Marcia. Entrevista [mensagem pessoal]. Mensagem recebida por <vaniadolores@oi.com.br> em 14 mar. 2010.

.Entrevista [mensagem pessoal]. Mensagem recebida por < vaniadolores@oi.com.br> em 25 jan. 2011.

. Seminário na Inauguração do Museu de Folclore Edison Carneiro. 1984. 1 cassete sonoro (60 min), mono, Vox 60 (transcrição).

FONSECA, Maria Cecília Londres. O patrimônio em processo: trajetória da política federal de preservação no Brasil. Rio de Janeiro: UFRJ/IPHAN, 1997.

FROTA, Lélia Coelho. Discurso na inauguração da exposição permanente do Museu de Folclore Edison Carneiro. Rio de Janeiro: INF, 1984, p. 4-5.

FUNARTE. Museu de Folclore Edison Carneiro. Rio de Janeiro, 1981. 88 p. il. (Museus Brasileiros, 5)

GONÇALVES, José Reginaldo Santos. O patrimônio como categoria de pensamento. In: ABREU, Regina e CHAGAS, Mario (orgs.). Memória e patrimônio: ensaios contemporâneos. Rio de Janeiro: DP\&A, 2003, p. 21-29.

HALBWACHS, Maurice. A memória coletiva. São Paulo: Vértice, 1990.189 p.

Les cadres sociaux de la mémoire. Paris: Les Presses universitaires de France, Nouvelle édition, 1952, 299 pages. Collection Bibliothèque de philosophie contemporaine. Disponível

em 
<http://www.uqac.uquebec.ca/zone30/Classiques des sciences sociales/index.html> Acesso em 25 jun. 2007.

INSTITUTO NACIONAL DO FOLCLORE. Museu de Folclore Edison Carneiro. Relatório. Rio de Janeiro, 1982.

MAGALHÃES, Aline Montenegro. Colecionando relíquias... um estudo sobre a Inspetoria de Monumentos Nacionais (1934-1937). 2004. 152 f. Dissertação (Mestrado em História Social) - Instituto de Filosofia e Ciências Sociais, Universidade Federal do Rio de Janeiro. Rio de Janeiro, 2004.

MENDONÇA, Elisabete. Tesauro e exposições permanentes de folclore e cultura popular: narrativas sobre arte popular elaboradas pelo Centro Nacional de Folclore e Cultura Popular (1980-2004[2006]). Tese (Doutorado em Artes Visuais). UFRJ, Programa de Pós-Graduação em Artes Visuais/Escola de Belas Artes, Rio de Janeiro, 2008.

MUSEU DE FOLCLORE EDISON CARNEIRO. Relatório. Rio de Janeiro: INF, [1972]. 3 páginas. Datilografado.

NAMER, Gerard. Les instituitions de mémoire culturelle. In: Mémoire et sociétè. Paris: Meridien, 1987. p. 159-185. (Collection Société).

NASCIMENTO, Bráulio do. Bráulio do Nascimento (Depoimento, 1988). Rio de Janeiro: CNFCP, 1988. Depoimento coletado no âmbito do projeto: "Os estudos do folclore no campo das ciências humanas e sociais/1988-RJ".

. Discurso de posse na direção-executiva da Campanha de Defesa do Folclore Brasileiro. Rio de Janeiro: CDFB, 1974. p. 1.

NORA, Pierre. Entre memória e história: a problemática dos lugares. Projeto História. São Paulo: Programa de estudos pós-graduados em História e do Departamento de História/PUC, n. 10, p. 7-28, dez. 1993.

NOTICIÁRIO. Revista Brasileira de Folclore. Rio de Janeiro: CDFB, v. 8, n. 21, mai./ago. 1968, p. 173-188.

176-180. Revista Brasileira de Folclore. Rio de Janeiro: CDFB, v. 9, n. 24, mai./ago. 1969, p. 263-273.

Revista Brasileira de Folclore. Rio de Janeiro: CDFB, v. 10, n. 28, set./dez. 1970, p.

OLIVEIRA, Vânia Dolores Estevam de. Museu de Folclore Edison Carneiro: poder, resistência e tensões na construção da memória da cultura popular brasileira. Tese (Doutorado) Universidade Federal do Estado do Rio de Janeiro, Programa de Pós Graduação em Memória Social, 2011.

ORTIZ, Renato. A moderna tradição brasileira: cultura brasileira e indústria cultural. São Paulo: Brasiliense, 2001.

Cultura brasileira e identidade nacional. 5 ed. São Paulo: Brasiliense, 1994. 
POLLAK, Michel. Memória, esquecimento, silêncio. Estudos Históricos. Rio de Janeiro, vol. 2, n. 3, 1989, p. 3-15.

PROPOSTA de Reestruturação da Campanha de Defesa do Folclore Brasileiro. Rio de Janeiro: CDFB, [1972].

SÁ, Ivan Coelho de. Curso de Museus - MHN, 1932-1978: alunos, graduandos e atuação profissional. Rio de Janeiro: Universidade Federal do Estado do Rio de Janeiro/Escola de Museologia, 2007. 270 p. Il.

SALLES, Vicente. Aquisição de peças folclóricas - Parecer. Rio de Janeiro: MEC/CDFB. 1968.

SILVA, Rita Gama. Quantos folclores brasileiros? As exposições permanentes do Museu de Folclore Edison Carneiro em perspectiva comparada. 2008. Dissertação (Mestrado em Sociologia e Antropologia) - Instituto de Filosofia e Ciências Sociais, Universidade Federal do Rio de Janeiro, Rio de Janeiro, 2008.

SIMÃO, Lucieni de Menezes. Os mediadores do patrimônio imaterial. Sociedade e cultura. Goiânia, v. 6, n. 1, p. 59-70, jan./jun. 2003.

VILHENA, Luis Rodolfo. Projeto e missão: o movimento folclórico brasileiro (1947-1964). Rio de Janeiro: Funarte / FGV, 1997. 